\title{
Impairment of synaptic plasticity and novel object recognition in the hypergravity-exposed rats
}

Jinho Lee ${ }^{1,4}$, Doohyeong Jang ${ }^{1,4}$, Hyerin Jeong ${ }^{1}$, Kyu-sung Kim ${ }^{2,3 凶}$ \& Sunggu Yang ${ }^{1 凶}$

The gravity is necessary for living organisms to operate various biological events including hippocampus-related functions of learning and memory. Until now, it remains inconclusive how altered gravity is associated with hippocampal functions. It is mainly due to the difficulties in generating an animal model experiencing altered gravity. Here, we demonstrate the effects of hypergravity on hippocampus-related functions using an animal behavior and electrophysiology with our hypergravity animal model. The hypergravity $(4 G, 4$ weeks) group showed impaired synaptic efficacy and long-term potentiation in CA1 neurons of the hippocampus along with the poor performance of a novel object recognition task. Our studies suggest that altered gravity affects hippocampus-related cognitive functions, presumably through structural and functional adaptation to various conditions of gravity shift.

Gravity shift renders living organisms to change their physiological properties and become evolved and adapted for stabilization to the current environment. Gravitational change such as microgravity (MG) and hypergravity $(\mathrm{HG})$ is the most influential stressor to terrestrial and aquatic creatures from Animalia to Plantae ${ }^{1-7}$. As for human, astronauts who experience both MG (in outer space) and HG (in launch and re-entry) ${ }^{8}$ suffer from various adverse symptoms ${ }^{9-11}$. Gravity shift from the space to Earth can be considered much larger HG to astronauts, and they are likely to spend a long time under intensive HG. Also, the level of HG used for the study on enhancement of drug effect is massive ${ }^{12-15}$. Under this condition, the central nervous system (CNS) is susceptible to gravity in the context of movement control, sensory integration, locomotion, balance, circadian rhythm, and hormone release $\mathrm{i}^{16-29}$.

Hippocampus is the essential part of CNS in light of learning and memory ${ }^{30-38}$. The effect of gravity on the hippocampus is investigated in various methods of behavioral, molecular, and electrophysiological aspects. MG causes the impaired discrimination of a new spatial arrangement ${ }^{39,40}$ and alteration in neural proteome ${ }^{39,41}$, gene expression $^{42}$ and cytomorphometry ${ }^{43}$. Interestingly, short-term exposure of HG (4G, $\left.48 \mathrm{~h}\right)$ results in enhanced LTP on $\mathrm{CA}^{44}$ while long-term exposure of $\mathrm{HG}$ (4G, 3 weeks) impairs spatial learning performance ${ }^{45}$. Various effects of gravity on hippocampus-related functions from genetic to molecular, behavioral, and electrophysiological levels are summarized in Table $1^{39-55}$, based on the duration and induction method of MG and HG. However, synaptic mechanism and behavioral consequence of HG on hippocampal functions still remain undetermined.

The aim of current study is to reveal a certain relationship between gravity and the hippocampal synaptic mechanisms underlying a cognitive function. For this, we employed a centrifugal system for gravity conditioning and electrophysiology (EPG) for observing synaptic responses of hippocampal CA1 neurons along with the behavior test of novel object recognition (NOR). Our results show that the ability to discriminate a novel object from the familiar one is impaired in the long-term exposure of HG (4 weeks) but not in the short-term exposure of HG (1 day). Furthermore, postsynaptic responses were reduced under long-term HG, largely due to the impairment of $\alpha$-amino-3-hydroxy-5-methyl-4-isoxazolepropionic acid receptors (AMPARs) and $N$-methyl-D-aspartate receptors (NMDARs). Here, we demonstrate that the long-term HG impairs hippocampus-related synaptic functions, therein suggesting the cellular mechanism of a HG-induced cognitive deficit and a therapeutic strategy.

${ }^{1}$ Department of Nano-Bioengineering, Incheon National University, Incheon, South Korea. ${ }^{2}$ Department of Otorhinolaryngology-Head and Neck Surgery, Inha University, College of Medicine, Incheon, South Korea. ${ }^{3}$ Inha Institute of Aerospace Medicine, Incheon, South Korea. ${ }^{4}$ These authors contributed equally: Jinho Lee and Doohyeong Jang. ${ }^{\varpi}$ email: stedman@inha.ac.kr; sungguyang@inu.ac.kr 


\begin{tabular}{|c|c|c|c|c|c|}
\hline Gravity & Exposure duration & Age condition & Strain & Effect of gravity on the hippocampus & References \\
\hline \multicolumn{6}{|l|}{ HG } \\
\hline \multirow{2}{*}{$1.85 \mathrm{G}$} & \multirow{2}{*}{$1 \mathrm{~h}$ for 5 days } & \multirow{2}{*}{$7-9$ weeks } & \multirow{2}{*}{ CD1 mice } & $\begin{array}{l}\text { Upregulation of expression level in synaptic plasticity-related gene } \\
\text { (proSAAS, neuroblastoma, thymosin beta-10, inhibin beta E) }\end{array}$ & 46 \\
\hline & & & & Damage on discriminating a new spatial arrangement & 47 \\
\hline \multirow[b]{2}{*}{$2 \mathrm{G}$} & 14 days & 8 weeks & C57BL/6J male mice & $\begin{array}{l}\text { Decreased brain-derived neurotrophic factor (BDNF) in the ventral } \\
\text { hippocampus-Increased 5-HT receptor 1B in the ventral hippocampus }\end{array}$ & 48 \\
\hline & 14 days & 7 weeks & Wistar male rats & $\begin{array}{l}\text { Impaired spatial memory (radial eight arms maze) } \\
\text { The same serum cortisol level with the control } \\
\text { Upregulation of insulin like growth factor binding protein } 2\end{array}$ & 49 \\
\hline \multirow{4}{*}{$3,4 \mathrm{G}$} & 14 days & $150-180 \mathrm{~g}$ & Wistar rats & $\begin{array}{l}\text { Impaired spatial learning task until } 5 \text { days, but no change after } 5 \text { days } \\
\text { (radial arm maze) }\end{array}$ & 50 \\
\hline & 14 days & - & Rats & No change of Input / output relationships and Long-term potentiation & 51 \\
\hline & 21 days & 8 weeks & C57BL/6J male mice & Impaired spatial learning performance (water maze) & 45 \\
\hline & $24,48 \mathrm{~h}$ & $8-9$ weeks & $\mathrm{C} 57 \mathrm{BL} / 6 \mathrm{~J}$ male mice & $\begin{array}{l}\text { No detrimental effect on basal neurotransmission } \\
\text { Increased LTP and phosphorylated AMPAR, but no change of L-LTP and } \\
\text { phosphorylated CREB }\end{array}$ & 44 \\
\hline \multicolumn{6}{|l|}{ MG } \\
\hline \multirow[b]{2}{*}{ Tail-suspension } & 7 days & $6-8$ weeks & $\mathrm{BALB} / \mathrm{c}$ mice & Major loss of proteins (tubulin, $\beta$-Synuclein) & 41 \\
\hline & 28 days & 8 weeks & SD rats & $\begin{array}{l}\text { The decline of learning and memory (Morris water maze) } \\
\text { Increased GluR1, GluR5, and glutamate whereas decreased 5-HT, dopa- } \\
\text { mine, GABA, and epinephrine }\end{array}$ & 39 \\
\hline \multirow[b]{2}{*}{ Hindlimb-suspension } & 14 days & 5-6 months & C57BL/6J male mice & $\begin{array}{l}\text { Alteration in TIC class (transport of small molecules and ions into the } \\
\text { cells): upregulation (Grin1) downregulation (Itga3) }\end{array}$ & 42 \\
\hline & 14 days & $225-275 \mathrm{~g}$ & Wistar rats & $\begin{array}{l}\text { Decreased mean area, perimeter, synaptic cleft, length of the active zone of } \\
\text { CA1 whereas increased dendritic arborization and number of spines } \\
\text { Unaltered mean thickness of postsynaptic density and total dendritic length }\end{array}$ & 43 \\
\hline \multirow[b]{2}{*}{ Space } & 7 days & - & SD rats & Elevated 5-HT1 receptor number & 52 \\
\hline & 16 days & 8, 14 days & SD rats & $\begin{array}{l}\text { Reversed spatial learning task performance (Morris water maze, radial arm } \\
\text { maze) }\end{array}$ & 40 \\
\hline
\end{tabular}

Table 1. Previous studies summarizing the physiological effects of altered gravity on hippocampus-related functions from genetic to molecular, behavioral, and electrophysiological levels.

a

\section{b}

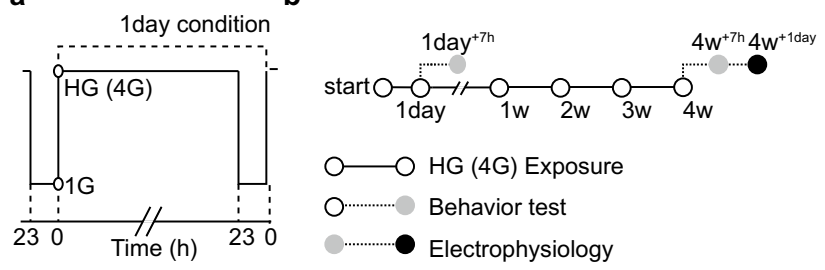

Figure 1. Conditioning and experiment procedure. (a) Schematic diagram showing HG exposure processes. It shows 1-day conditioning process that comprises $23 \mathrm{~h} \mathrm{HG}$ exposure followed by 1 -h rest period. It is repeated for 4 weeks. (b) Schematic diagram for overall time schedule: HG exposure (1 day or 4 weeks), behavior test (7 h), and EPG (21 h).

\section{Experimental procedures}

Animals. About 11 weeks old male Sprague-Dawley (SD) rats were used for electrophysiology and animal behavior test. All animal handling procedures were approved by the Institutional Animal Care and Use Committee of Inha University (INHA 180105-533) and Incheon National University (INU-ANIM-2017-08), and all experiments were performed in accordance with relevant guidelines and regulations.

Hypergravity exposure. SD rats were conditioned by HG (4G) induced in a gravitational force simulator with two horizontal rotatory arms (50 cm long each). When the arms were rotated, centrifugal force was delivered to the animal cage locating at the end of arms. When the arms rotated at a speed of $65 \mathrm{rpm}$, rats in the cage were exposed to $4 \mathrm{G}$. A high-resolution camera inside the cage was used to observe whether rats were able to move freely and access food and water. The rats were exposed to HG for $23 \mathrm{~h}$ and took an hour rest under normal gravity (1G). The conditioning process was repeated for 1 day $\left(\mathrm{HG}_{1 \text { day }}\right)$ or 4 weeks $\left(\mathrm{HG}_{4 \text { weeks }}\right)$ (Fig. 1a). The behavior test and EPG were conducted in $24 \mathrm{~h}$ right after the rats were released from HG (Fig. 1b).

Behavior test of a novel object recognition. NOR test comprised two phases. Each phase with 10 min duration was separated by a 6 -h inter-phase interval. During the first phase of the familiarization period, the rat was presented in a pair of identical, familiar objects $\left(\mathrm{F}_{1}, \mathrm{~F}_{2}\right)$ in a white acrylic open field box $(60 \mathrm{~cm}$ width $\times 60 \mathrm{~cm}$ 
length $\times 60 \mathrm{~cm}$ height) to be habituated to environmental factors including the place of objects. The two objects were placed in a diagonal position about $5 \mathrm{~cm}$ away from the white wall (Fig. 2a). The exploratory movement of the rat during the phase was recorded with a video camera installed at the top of the apparatus. In completing the first phase, the rat and familiar objects $\left(\mathrm{F}_{1}, \mathrm{~F}_{2}\right)$ were removed from the apparatus for $6 \mathrm{~h}$. In the second phase, the test phase, the rat explored a third copy of the familiar object $\left(\mathrm{F}_{3}\right)$ and a novel object $(\mathrm{N})$ in the apparatus. Rats used to explore the novel object $(\mathrm{N})$ more than the familiar one $\left(\mathrm{F}_{3}\right)$. To eliminate a certain variation by emotional instability, rats with excessive freezing behavior more than $60 \%$ ( $>360 \mathrm{~s}$ ) out of the whole period of test phase (10 mins) were excluded from analysis (Exclusion : $1 \mathrm{G}-3$ out of 10 rats; $\mathrm{HG}_{1 \text { day }} \mathrm{HG}_{4 \text { weeks }}$ - each 1 out of 5 rats). Object exploration was defined when the nose of the rats directed towards the object at a distance below $2 \mathrm{~cm}$ and measured by the discrimination index which indicates the difference of time spent between a novel $\left(\mathrm{T}_{\mathrm{N}}\right)$ and familiar object $\left(\mathrm{T}_{\mathrm{F} 3}\right)$. It was calculated with the total amount of time spent with both objects in the test phase $\left[\right.$ Discrimination Index $\left.=\left(\mathrm{T}_{\mathrm{N}}-\mathrm{T}_{\mathrm{F} 3}\right) /\left(\mathrm{T}_{\mathrm{N}}+\mathrm{TF}_{3}\right)\right]$.

Brain slice preparation. Age matched conditioned (HG group) and unconditioned (1G group) rats were deeply anesthetized with $2 \%$ isoflurane. Motionless rats were decapitated by a guillotine, and the brain was isolated quickly. The isolated brain was transferred to the ice-cold dissection buffer containing the following ingredients (in mM): 25 glucose, 75 sucrose, $87 \mathrm{NaCl}, 2.5 \mathrm{KCl}, 1.3 \mathrm{NaH}_{2} \mathrm{PO}_{4}, 25 \mathrm{NaHCO}_{3}, 7.0 \mathrm{MgCl}_{2}$, and $0.5 \mathrm{CaCl}_{2}$ bubbled with a mixture of $5 \% \mathrm{CO}_{2}$ and $95 \% \mathrm{O}_{2}$. The hippocampus including Schaffer collaterals (SC) was isolated from the whole brain and transversely sectioned into $400 \mu \mathrm{m}$ thick slices using Leica VT1200S vibratome (Leica Biosystems, Wetzlar, Germany) filled with the same buffer. The slices were incubated for $12 \mathrm{~min}$ at $32{ }^{\circ} \mathrm{C}$ and recovered for $1 \mathrm{~h}$ at room temperature, submerged in the artificial cerebral spinal fluid (aCSF) containing the following ingredients (in mM): 25 glucose, $125 \mathrm{NaCl}, 2.5 \mathrm{KCl}, 1.3 \mathrm{NaH}_{2} \mathrm{PO}_{4}, 25 \mathrm{NaHCO}_{3}, 1.0 \mathrm{MgCl}_{2}$, and 2.0 $\mathrm{CaCl}_{2}$ bubbled with a mixture of $5 \% \mathrm{CO}_{2}$ and $95 \% \mathrm{O}_{2}$.

In vitro field recording. Slices were transferred to a recording chamber where aCSF flowed $\left(31 \pm 0.5^{\circ} \mathrm{C}\right.$; $1-2 \mathrm{ml} / \mathrm{min}$ ). A slice harp anchored the slices in order to stabilize the recording position. A bipolar stimulating electrode was placed on the SC to evoke field excitatory postsynaptic potential (fEPSP) which were recorded on the stratum radiatum (SR) of CA1 by glass electrodes filled with aCSF. All responses were acquired using Axon Digidata 1550B 8-Channel Digitizer (Molecular Devices, San Jose, CA) and amplified using MultiClamp 700B Microelectrode amplifier (Molecular Devices, San Jose, CA, USA). The maximum slope of fEPSPs was identified in the establishment of input-output (I/O) relationship. Half maximal fEPSPs were used for high frequency stimulation (HFS: $100 \mathrm{~Hz}, 1 \mathrm{~s}$ ) for LTP induction.

Data analysis. All electrophysiological data were presented numerically using Axon pCLAMP11 Electrophysiology Data Acquisition and Analysis Software (Molecular Devices, San Jose, CA). The difference in behavior assessment was measured by One-way analysis of variance (ANOVA) of the Bonferroni post-hoc test. Two-way ANOVA was used to assess statistical significance for the differences between HG and 1G groups in EPG. Every statistical process was performed on SPSS Statics 25 (IBM, Armonk, NY). At least $p<0.05$ was interpreted statistically significant $\left({ }^{*} \mathrm{p}<0.05,{ }^{* *} \mathrm{p}<0.01,{ }^{* * *} \mathrm{p}<0.001\right)$. All Graphs were prepared by GraphPad Prism 7 (GraphPad Software Inc., La Jolla, CA, USA) and final arrangement and labeling were carried out using Adobe Illustrator CC 2019 (Adobe Inc., San Jose, CA, USA). All data are presented in mean \pm standard error of the mean (SEM). N indicates the number of animals in the NOR test and slices in EPG.

\section{Result}

Impaired NOR in rats under HG. We wondered whether the gravity affects memory-related behavior according to an exposure time of $\mathrm{HG}$. The NOR task was conducted with rats under normal gravity, $\mathrm{HG}_{1 \text { day }}$ and $\mathrm{HG}_{4 \text { weeks }}$ in open field box (Fig. 2a,b). Rats showed similar preference for each object regardless of $\mathrm{HG}$ in the familiarization phase (Fig. $2 \mathrm{c} ; 1 \mathrm{G}-\mathrm{F}_{1}: 31.50 \pm 5.64, \mathrm{~F}_{2}: 37.58 \pm 9.40, p=0.590, \mathrm{HG}_{1 \mathrm{day}}-\mathrm{F}_{1}: 31.32 \pm 4.79, \mathrm{~F}_{2}$ : $\left.30.40 \pm 5.73, p=0.906, \mathrm{HG}_{4 \text { weeks }}-\mathrm{F}_{1}: 59.28 \pm 10.82, \mathrm{~F}_{2}: 52.37 \pm 10.46, p=0.662\right) .1 \mathrm{G}$ and $\mathrm{HG}_{1 \text { day }}$ had a preference for novel objects in the test phase but not $\mathrm{HG}_{4 \text { weeks }}$ rats (Fig. $2 \mathrm{~d} ; 1 \mathrm{G}-\mathrm{F}_{3}: 27.20 \pm 3.12, \mathrm{~N}: 51.28 \pm 4.06, p<0.001$, $\left.\mathrm{HG}_{1 \text { day }}-\mathrm{F}_{3}: 22.46 \pm 1.80, \mathrm{~N}: 47.38 \pm 10.14, p=0.052, \mathrm{HG}_{4 \text { weeks }} \mathrm{F}_{3}: 45.19 \pm 7.56, \mathrm{~N}: 43.09 \pm 5.59, p=0.831\right)$. Discriminating competence differed between groups (Fig. $2 \mathrm{e} ; 1 \mathrm{G}-0.31 \pm 0.03, \mathrm{n}=7$ rats, $\mathrm{HG}_{1 \text { day }}-0.33 \pm 0.06$, $\mathrm{n}=4$ rats, $\mathrm{HG}_{4 \text { weeks }}-0.02 \pm 0.04, \mathrm{n}=4$ rats, $\left.F_{2,12}=18.224, p<0.001\right)$. The $1 \mathrm{G}$ and $\mathrm{HG}_{1 \text { day }}$ groups preferred a novel object whereas the $\mathrm{HG}_{4 \text { weeks }}$ group showed the similar preference toward both objects (posttest: $1 \mathrm{G}$ vs. $\mathrm{HG}_{1 \text { day }}-p=1.000,1 \mathrm{G}$ vs. $\mathrm{HG}_{4 \text { weeks }}-p<0.001, \mathrm{HG}_{1 \text { day }}$ vs. $\mathrm{HG}_{4 \text { weeks }}-p=0.001$ ). To determine if $\mathrm{HG}$ influences motivation and locomotion for rats to explore, total exploration time was measured (Fig. 2f; $1 \mathrm{G}-78.47 \pm 6.91$, $\mathrm{n}=7$ rats, $\mathrm{HG}_{1 \mathrm{day}}-69.84 \pm 11.74, \mathrm{n}=4$ rats, $\mathrm{HG}_{4 \text { weeks }}-88.28 \pm 12.78, \mathrm{n}=4$ rats, $\left.F_{2,12}=0.727, p=0.503\right)$, showing no significant difference between all groups. It indicates that $\mathrm{HG}_{4 \text { weeks }}$ impairs the ability to discriminate a novel object from the familiar one.

Reduced postsynaptic, but not presynaptic transmission under HG. In order to examine whether HG affects synaptic events in the hippocampal CA1 network, we tested the synaptic transmission of CA1 pyramidal cells in response to SC stimulation. The fiber volley (FV), the indicator of $\mathrm{Ca}^{2+}$ influx into the presynaptic axon terminal, was considered as the input while the slope of postsynaptic fEPSPs, mostly AMPARs-mediated responses, was taken as the output. As predicted, the slope of fEPSPs increased as the amplitude of FVs increased in both groups (Fig. $3 \mathrm{a}, \mathrm{b} ; 1 \mathrm{G}-0.2 \mathrm{mV}: 0.15 \pm 0.02, \mathrm{n}=27$ slices, $0.4 \mathrm{mV}: 0.38 \pm 0.03, \mathrm{n}=30$ slices, $0.6 \mathrm{mV}: 0.66 \pm 0.14, \mathrm{n}=14$ slices; $\mathrm{HG}-0.2 \mathrm{mV}: 0.08 \pm 0.01, \mathrm{n}=30$ slices, $0.4 \mathrm{mV}: 0.23 \pm 0.06, \mathrm{n}=22$ slices, $0.6 \mathrm{mV}$ : $0.34 \pm 0.11, \mathrm{n}=10$ slices). However, the significant deficit of synaptic transmission was observed in the HG group 

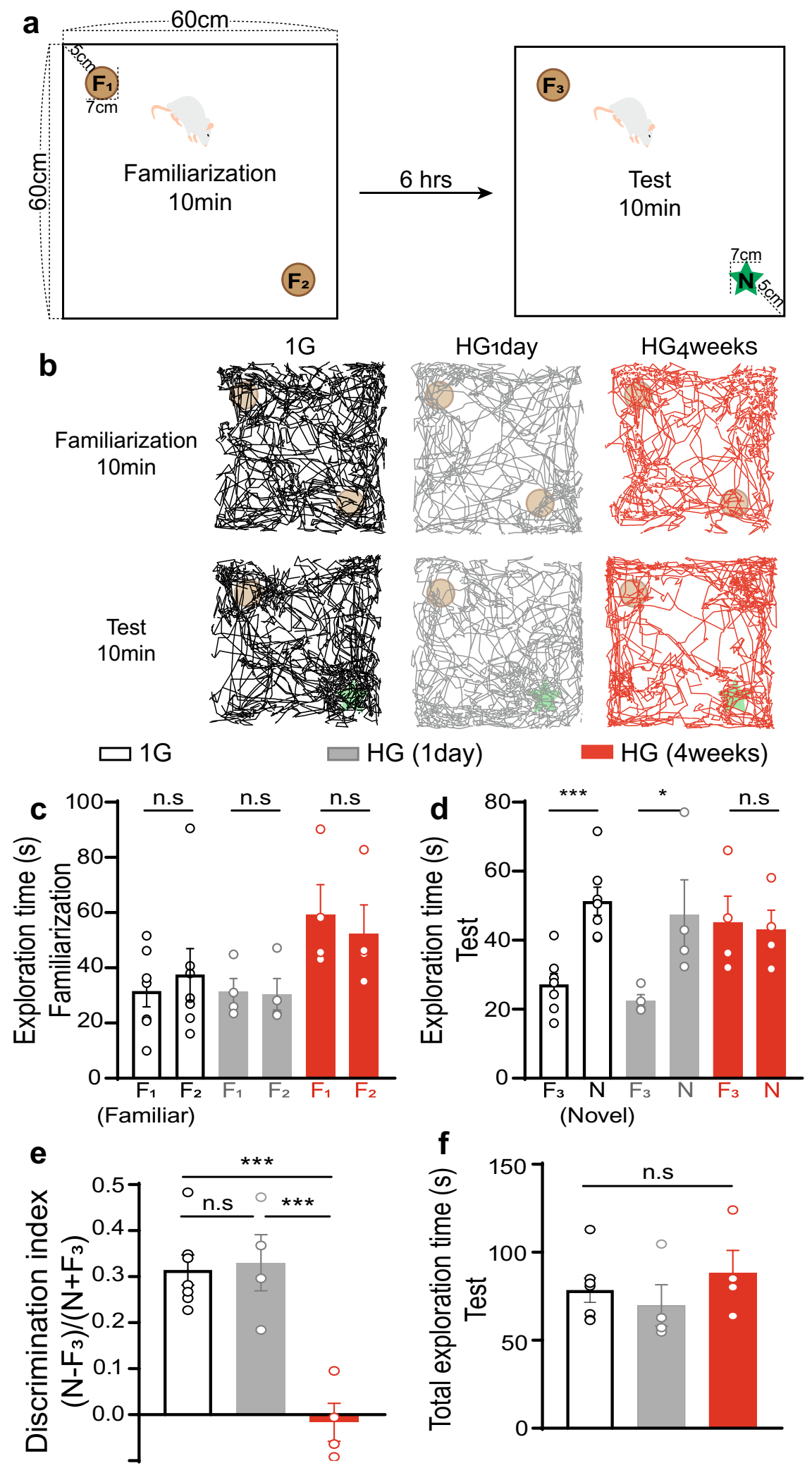

Figure 2. Novel object recognition (NOR) test with $1 G$ and $H G$ rats. (a) The scheme of arena and the position of objects. (b) Representative traces of $1 \mathrm{G}, \mathrm{HG}_{1 \mathrm{day}}$ and $\mathrm{HG}_{4 \text { weeks }}$ for each phase (familiarization and test). (c) Exploration times for each object during the familiarization phase. (d) $\mathrm{HG}_{4 \text { weeks }}$ group had no preference for both $\mathrm{F}_{3}$ and $\mathrm{N}$ objects during the test phase. (e) Discrimination indexes are plotted as a function of the $1 \mathrm{G}$ and $\mathrm{HG}$ groups. $\mathrm{HG}_{4 \text { weeks }}$ impairs the discrimination of novel objects. (f) Total exploration time does not show any differences between the groups. ${ }^{*} \approx 0.05^{* * *}<0.001, n$.s not significant. 
a

$-1 \mathrm{G}$
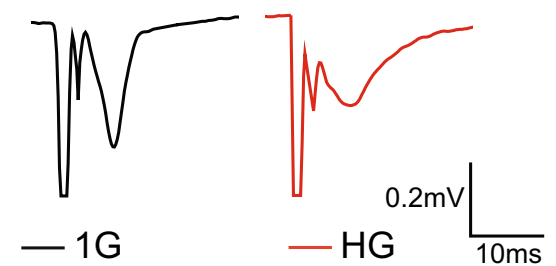

C

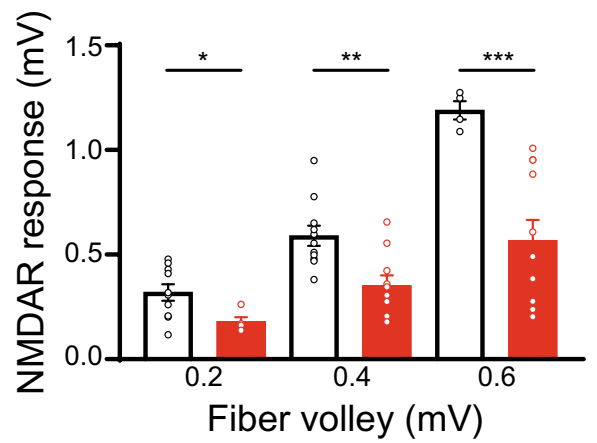

b

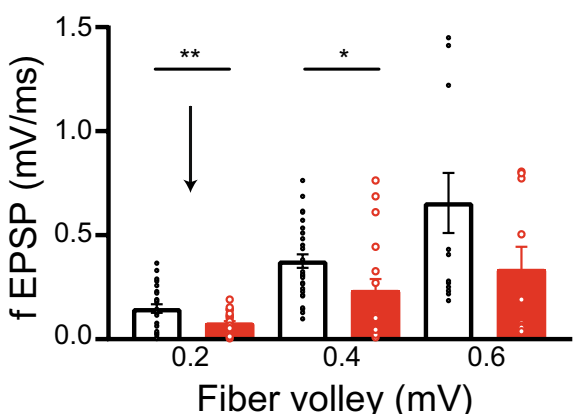

d

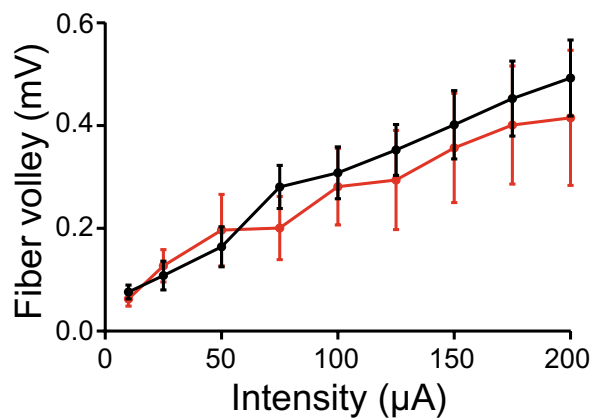

Figure 3. Impaired postsynaptic AMPAR / NMDAR function, but not presynaptic transmission, in the hippocampal CA1 network. (a) Representative traces of FVs and fEPSPs at $0.2 \mathrm{mV}$ (from the arrow in b). (b) The slope of fEPSPs as the function of the increasing amplitudes of FVs. HG reduces fEPSPs at 0.2 and $0.4 \mathrm{mV}$ FVs. (c) Pharmacologically isolated NMDAR mediated responses over the increasing FVs in the presence of $10 \mu \mathrm{M}$ NBQX and $0 \mathrm{mM} \mathrm{MgCl}$. HG reduces the amplitude of NMDAR responses at all FVs. (d) The amplitude of FVs over various stimulus intensities does not show any difference between $1 \mathrm{Gl}$ and $\mathrm{HG}$ groups.

when it is compared to that in the $1 \mathrm{G}$ group $\left(F_{1,127}=14.747, p<0.001\right)$. A post-hoc Student's $t$ tests showed the significant difference in output at 0.2 and $0.4 \mathrm{mV}\left(t_{0.2 \mathrm{mV}}=3.091, p_{0.2 \mathrm{mV}}=0.004, t_{0.4 \mathrm{mV}}=2.217, p_{0.4 \mathrm{mV}}=0.033\right.$, $\left.t_{0.6 \mathrm{mV}}=1.766, p_{0.6 \mathrm{mV}}=0.091\right)$. Next, to test whether the response difference is attributed to altered function of NMDARs, NMDAR response as the function of FVs was measured in the presence of $10 \mu \mathrm{M} \mathrm{NBQX}$, an AMPAR antagonist, and $0 \mathrm{mM} \mathrm{MgCl}_{2}$, an NMDAR-enhancing chemical We found that the HG group had the significant reduction in NMDAR response when compared with that of the $1 \mathrm{G}$ group (Fig. $3 \mathrm{c} ; 1 \mathrm{G}-0.2 \mathrm{mV}: 0.32 \pm 0.04$, $\mathrm{n}=10$ slices, $0.4 \mathrm{mV}: 0.60 \pm 0.10, \mathrm{n}=12$ slices, $0.6 \mathrm{mV}: 1.19 \pm 0.04, \mathrm{n}=4$ slices; $\mathrm{HG}-0.2 \mathrm{mV}: 0.18 \pm 0.02, \mathrm{n}=5$ slices, $0.4 \mathrm{mV}: 0.35 \pm 0.05, \mathrm{n}=10$ slices, $0.6 \mathrm{mV}: 0.57 \pm 0.10, \mathrm{n}=11$ slices; $\mathrm{F}_{1,46}=32.989, \mathrm{p}<0.001$ ). A post-hoc Student's $t$ tests showed the significant difference at all intensities of FVs $\left(t_{0.2 \mathrm{mV}}=2.399, p_{0.2 \mathrm{mV}}=0.032, t_{0.4 \mathrm{mV}}=3.704\right.$, $\left.p_{0.4 \mathrm{mV}}=0.001, t_{0.6 \mathrm{mV}}=5.779, p_{0.6 \mathrm{mV}}<0.001\right)$. Also, the amplitude of FVs was measured over various intensities in order to test whether $\mathrm{HG}$ affects presynaptic transmission. In the HG group, there was no deficit of FV responses over the increasing intensities. (Fig. $3 \mathrm{~d}$; $1 \mathrm{G}-10 \mu \mathrm{A}: 0.08 \pm 0.01, \mathrm{n}=8$ slices, $25 \mu \mathrm{A}: 0.11 \pm 0.03, \mathrm{n}=8$ slices, $50 \mu \mathrm{A}$ : $0.16 \pm 0.04, \mathrm{n}=8$ slices, $75 \mu \mathrm{A}: 0.28 \pm 0.04, \mathrm{n}=8$ slices, $100 \mu \mathrm{A}: 0.31 \pm 0.05, \mathrm{n}=8$ slices, $125 \mu \mathrm{A}: 0.35 \pm 0.05, \mathrm{n}=8$ slices, $150 \mu \mathrm{A}: 0.40 \pm 0.07, \mathrm{n}=7$ slices, $175 \mu \mathrm{A}: 0.45 \pm 0.07, \mathrm{n}=7$ slices, $200 \mu \mathrm{A}: 0.49 \pm 0.07, \mathrm{n}=7$ slices; HG-10 $\mu \mathrm{A}: 0.05 \pm 0.02, \mathrm{n}=7$ slices, $25 \mu \mathrm{A}: 0.13 \pm 0.03, \mathrm{n}=7$ slices, $50 \mu \mathrm{A}: 0.20 \pm 0.07, \mathrm{n}=7$ slices, $75 \mu \mathrm{A}: 0.20 \pm 0.06, \mathrm{n}=7$ slices, $100 \mu \mathrm{A}: 0.28 \pm 0.07, \mathrm{n}=7$ slices, $125 \mu \mathrm{A}: 0.29 \pm 0.10, \mathrm{n}=7$ slices, $150 \mu \mathrm{A}: 0.36 \pm 0.11, \mathrm{n}=7$ slices, $175 \mu \mathrm{A}$ : $0.40 \pm 0.11, \mathrm{n}=7$ slices, $200 \mu \mathrm{A}: 0.42 \pm 0.13, \mathrm{n}=7$ slices; $\left.F_{1,114}=1.152, p=0.285\right)$. Our data demonstrate that HG likely damages the postsynaptic function in the SC-CA1 synapse.

Altered LTP in HG. To test whether HG has an effect on synaptic plasticity, we examine short-term and long-term synaptic plasticity in both the $1 \mathrm{G}$ and HG groups. When SC was activated by the paired pulse with various intervals, differential paired pulse facilitation (PPF) was observed as the slope of the second fEPSPs (P2) over the first fEPSPs (P1) in both groups (Fig. 4a). There was no statistical significance between the two groups $(\mathrm{G}-50 \mathrm{~ms}: 1.98 \pm 0.23, \mathrm{n}=9$ slices, $100 \mathrm{~ms}: 1.77 \pm 0.17, \mathrm{n}=9$ slices, $250 \mathrm{~ms}: 1.24 \pm 0.07, \mathrm{n}=9$ slices, 500 ms: $1.10 \pm 0.07, \mathrm{n}=9$ slices, $\mathrm{HG}-50 \mathrm{~ms}: 1.95 \pm 0.20, \mathrm{n}=14$ slices, $100 \mathrm{~ms}: 1.89 \pm 0.20, \mathrm{n}=16$ slices, $250 \mathrm{ms:}$ $1.22 \pm 0.06, \mathrm{n}=13$ slices, $500 \mathrm{~ms}: 1.09 \pm 0.06, \mathrm{n}=15$ slices; $\left.F_{1,86}=0.011, p=0.915\right)$. It is remarkable to observe that LTP was diminished in the HG group (Fig. 4b; $1 \mathrm{G}$-baseline: $101.28 \pm 2.15$, post HFS: $158.71 \pm 4.91, \mathrm{n}=11$ slices; HG-baseline: $102.27 \pm 2.13$, post HFS: $110.65 \pm 2.87, \mathrm{n}=13$ slices; $F_{1,220}=73.070, p=0.001$ ). Our results suggest that the gravity shift plays a critical role in the long-term synaptic plasticity. 
a

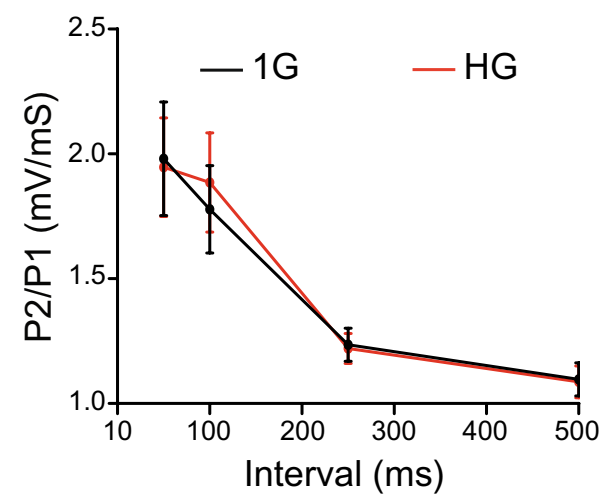

b

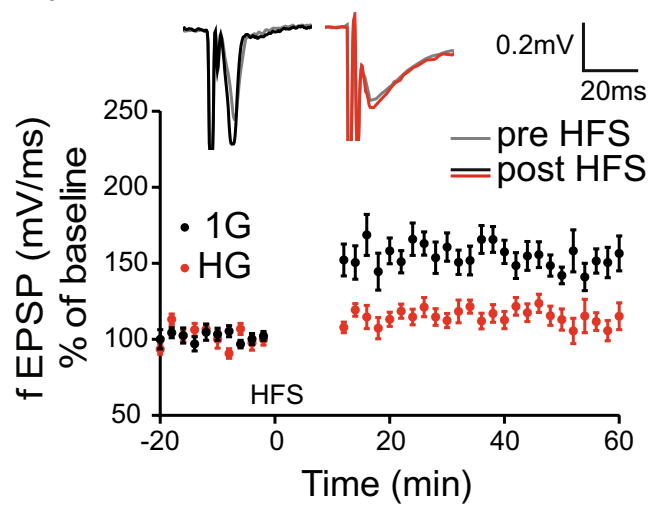

Figure 4. Impaired long-term synaptic plasticity under HG. (a) PPF was calculated by the P2/P1 ratio over various inter-stimulus intervals. P2/P1 of HG groups is not significantly different from that of $1 \mathrm{G}$ groups. (b) HG impairs LTP induced by HFS. Representative traces of both baselines (gray line) and LTP after HFS (black and red lines) are indicated, showing a negligible increase of LTP under HG.

\section{Discussion}

It has been well studied that the vestibular system is greatly affected by altered gravity ${ }^{21,22,56-58}$. The previous study implied that the vestibular organ was the main area influenced by HG in the brain ${ }^{48}$. Notably, the hippocampus, especially CA1, had electrophysiological and anatomical connections with the vestibular system ${ }^{59-66}$. For example, lesioned hippocampus aggravated HG-induced motion sickness ${ }^{53}$. The fact that HG has adverse effects on the brain triggered us to investigate a hippocampal function after the HG conditioning. Our current findings are as follows (1) $\mathrm{HG}_{4 \text { weeks }}$ causes the behavioral deficit in the NOR test; (2) $\mathrm{HG}_{4 \text { weeks }}$ impairs AMPARs/NMDARsmediated synaptic transmission; (3) $\mathrm{HG}_{4 \text { weeks }}$ group shows abnormal postsynaptic (but normal presynaptic) responses; and (4) $\mathrm{HG}_{4 \text { weeks }}$ alters LTP.

Differential effects of HG on pre- and post-synaptic neurons. Neurotransmitter release is determined by the incidence and pattern of action potentials, depolarization of nerve terminals, and release probability of vesicle machinery ${ }^{67-70}$. The previous study investigating the synaptosome in cerebral hemispheres showed that HG alters neurotransmitter release by modulation of neurotransmitter reuptake, indicating a role of HG in a presynaptic mechanism ${ }^{71}$. However, in our study, there was no significant difference of presynaptic FV amplitude over stimulation intensities and PPF representing presynaptic $\mathrm{Ca}^{2+}$ influx and neurotransmitter releaseprobability, respectively. It demonstrates that HG does not alter the presynaptic activity at least in CA3-CA1 network. Instead, the strong reliance on postsynaptic AMPAR/NMDAR responses under HG condition depicts a postsynaptic mechanism. This finding is consistent with our early study that HG causes the impaired function of postsynaptic AMPAR and metabotropic glutamate receptors (mGluRs) subtype 1 in the cerebellum ${ }^{72}$.

A role of HG in cognitive behaviors and plasticity. Previous studies showed that HG causes various physiological changes, such as vestibular function ${ }^{73}$, signaling pathway in muscles ${ }^{74}$, and bone formation ${ }^{75}$ which can lead to altered behaviors. As expected, our research group also observed that HG causes an abnormality of cerebellum-dependent motor coordination ${ }^{72}$. Now, our view is expanded to investigate a role of HG in cognitive behaviors with a memory test. HG-driven poor performance in NOR may be affected by a defect of memory function because NOR is dominantly dependent on the hippocampus ${ }^{76-80}$. Our result suggests that HG directly triggers the dysfunction of the hippocampus-dependent cognitive behavior. Given our and other results, HG could accompany multiple, parallel processing of various physiological systems such as HG to vestibular/motor behaviors and HG to cognitive behaviors.

It is previously well known that NMDARs are deeply involved in neural plasticity and often behaviors ${ }^{32,36,81-83}$. A previous study described an increased LTP under short-term exposure of $4 \mathrm{G}(48 \mathrm{~h})^{44}$. Meanwhile, we observed that the long-term, but not short-term, exposure of $4 \mathrm{G}$ ( 4 weeks) impairs a cognitive behavior followed by LTP deficit. Prior studies (various gravity levels, 3 weeks) revealed that HG-induced abnormality in various behaviors was sustained even after 15 days from centrifugation ${ }^{45}$. In our experimental condition, it seems to be worth testing how long the HG effect lasts.

Therapeutic strategy for HG. This study provides the scientific aspect of physiological effects by HG on hippocampus. Long-term gravity shift can cause the impairment of electrophysiological property in the hippocampus and the behavior in the NOR task, and it could be due to a defect of postsynaptic receptors. Therefore, HG-induced impairment may have the potential to be rescued by restoring the function of postsynaptic receptors. We have previously proposed transient potassium channels as a therapeutic target for various brain disorders. It is because the transient potassium channels are electrically counteracting channels to NMDARs and have clinical benefits of minimal interference in a normal synaptic transmission which can be impaired under 
the pharmacological modulation of NMDARs ${ }^{84,85}$. A pharmacological approach to enhance an NMDAR function can be further investigated under the condition of altered gravity.

Received: 12 December 2019; Accepted: 24 August 2020

Published online: 25 September 2020

\section{References}

1. Goldermann, M. \& Hanke, W. Ion channel are sensitive to gravity changes. Microgravit. Sci. Technol. 13, 35-38 (2001).

2. Ilyin, E. A. \& Oganov, V. S. Microgravity and musculoskeletal system of mammals. Adv. Sp. Res. 9, 11-19 (1989).

3. Gustave Dit Duflo, S., Gestreau, C. \& Lacour, M. Fos expression in the rat brain after exposure to gravito-inertial force changes. Brain Res. 861, 333-344 (2000).

4. Cox, J. F. et al. Influence of microgravity on astronauts' sympathetic and vagal responses to Valsalva's manoeuvre. J. Physiol. 538, 309-320. https://doi.org/10.1113/jphysiol.2001.012574 (2002).

5. Gharib, C. \& Custaud, M. A. Orthostatic tolerance after spaceflight or simulated weightlessness by head-down bed-rest. Bull. Acad. Natl. Med. 186, 733-746 (2002).

6. Chabbert, C., Brugeaud, A., Lennan, G., Lehouelleur, J. \& Sans, A. Electrophysiological properties of the utricular primary transducer are modified during development under hypergravity. Eur. J. Neurosci. 17, 2497-2500 (2003).

7. Rahmann, H., Slenzka, K., Kortje, K. H. \& Hilbig, R. Synaptic plasticity and gravity: Ultrastructural, biochemical and physicochemical fundamentals. Adv. Sp. Res. 12, 63-72 (1992).

8. Pompeiano, O. et al. Immediate early gene expression in the vestibular nuclei and related vegetative areas in rats during space flight. Acta Otolaryngol. Suppl. 545, 120-126 (2001).

9. Heer, M. \& Paloski, W. H. Space motion sickness: Incidence, etiology, and countermeasures. Auton. Neurosci. 129, 77-79 (2006).

10. Van Ombergen, A. et al. Brain tissue-volume changes in cosmonauts. N. Engl. J. Med. 379, 1678-1680. https://doi.org/10.1056/ NEJMc1809011 (2018).

11. Roberts, D. R. et al. Effects of spaceflight on astronaut brain structure as indicated on MRI. N. Engl. J. Med. 377, 1746-1753. https ://doi.org/10.1056/NEJMoa1705129 (2017).

12. Kim, D., Kim, Y. H. \& Kwon, S. Enhanced nasal drug delivery efficiency by increasing mechanical loading using hypergravity. Sci. Rep. 8, 168 (2018)

13. Jang, T. Y., Jung, A.-Y., Kwon, S. \& Kim, Y. H. Hypergravity enhances the therapeutic effect of dexamethasone in allergic asthma and rhinitis animal model. PLoS One 13, e0197594 (2018).

14. Genchi, G. G. et al. Hypergravity as a tool for cell stimulation: Implications in biomedicine. Front. Astronomy Sp. Sci. 3, 26 (2016).

15. Cogoli, A. The effect of hypogravity and hypergravity on cells of the immune system. J. Leukoc. Biol. 54, 259-268 (1993).

16. Rosenzweig, M. R., Bennett, E. L. \& Diamond, M. C. Brain changes in response to experience. (1972).

17. Fuller, C. A. The effects of gravity on the circadian timing system. J. Gravit. Physiol. 1, P1-4 (1994).

18. Daunton, N. G., Tang, F., Corcoran, M. L., Fox, R. A. \& Man, S. Y. Chronic exposure to hypergravity affects thyrotropin-releasing hormone levels in rat brainstem and cerebellum. Biol. Signals Recept. 7, 337-344. https://doi.org/10.1159/000014557 (1998).

19. Marušič, U., Meeusen, R., Pišot, R. \& Kavcic, V. The brain in micro-and hypergravity: The effects of changing gravity on the brain electrocortical activity. Eur. J. Sport Sci. 14, 813-822 (2014).

20. Jang, T. Y., Jung, A. Y. \& Kim, Y. H. Hormetic effect of chronic hypergravity in a mouse model of allergic asthma and rhinitis. Sci. Rep. 6, 27260. https://doi.org/10.1038/srep27260 (2016).

21. Gaboyard, S., Sans, A. \& Lehouelleur, J. Differential impact of hypergravity on maturating innervation in vestibular epithelia during rat development. Brain Res. Dev. Brain Res. 143, 15-23 (2003).

22. Bruce, L. L. Adaptations of the vestibular system to short and long-term exposures to altered gravity. Adv. Sp. Res. 32, 1533-1539. https://doi.org/10.1016/S0273-1177(03)90392-9 (2003).

23. Kramer, A., Gollhofer, A. \& Ritzmann, R. Acute exposure to microgravity does not influence the H-reflex with or without whole body vibration and does not cause vibration-specific changes in muscular activity. J. Electromyogr. Kinesiol. 23, 872-878 (2013).

24. Ritzmann, R., Freyler, K., Weltin, E., Krause, A. \& Gollhofer, A. Load dependency of postural control-kinematic and neuromuscular changes in response to over and under load conditions. PLoS One 10, e0128400 (2015).

25. Schaffhauser, D. F. et al. Microfluidic platform for electrophysiological studies on Xenopus laevis oocytes under varying gravity levels. Lab Chip 11, 3471-3478 (2011).

26. Sato, T., Miyoshi, T., Nakazawa, K., Yano, H. \& Takeoka, H. Reflex response changes during hyper and microgravity. J. Gravit. Physiol. 8, P97-99 (2001).

27. Ohira, Y., Nomura, T., Kawano, F., Soduh, M. \& Ishihara, A. Responses of Hoffman-reflex in human soleus to gravity and/or fluid shift. J. Gravit. Physiol. 9, P129-130 (2002).

28. Miyoshi, T. et al. Somatosensory graviception inhibits soleus H-reflex during erect posture in humans as revealed by parabolic flight experiment. Exp. Brain Res. 150, 109-113 (2003).

29. Crone, C. et al. Sensitivity of monosynaptic test reflexes to facilitation and inhibition as a function of the test reflex size: A study in man and the cat. Exp. Brain Res. 81, 35-45 (1990).

30. Jarrard, L. E. On the role of the hippocampus in learning and memory in the rat. Behav. Neural Biol. 60, 9-26. https://doi. org/10.1016/0163-1047(93)90664-4 (1993).

31. Broadbent, N. J., Squire, L. R. \& Clark, R. E. Spatial memory, recognition memory, and the hippocampus. Proc. Natl. Acad. Sci. USA 101, 14515-14520. https://doi.org/10.1073/pnas.0406344101 (2004).

32. Yang, S. et al. Interlamellar CA1 network in the hippocampus. Proc. Natl. Acad. Sci. USA 111, 12919-12924. https://doi.org/10.1073/ pnas.1405468111 (2014).

33. Sun, D. G. et al. Long term potentiation, but not depression, in interlamellar hippocampus CA1. Sci. Rep. 8, 5187. https://doi. org/10.1038/s41598-018-23369-4 (2018).

34. LeGates, T. A. et al. Aberrant light directly impairs mood and learning through melanopsin-expressing neurons. Nature 491, 594-598. https://doi.org/10.1038/nature11673 (2012).

35. Yang, S., Santos, M. D., Tang, C. M., Kim, J. G. \& Yang, S. A postsynaptic role for short-term neuronal facilitation in dendritic spines. Front Cell Neurosci. 10, 224. https://doi.org/10.3389/fncel.2016.00224 (2016).

36. Yang, S. et al. Integrity of mGluR-LTD in the associative/commissural inputs to CA 3 correlates with successful aging in rats. J. Neurosci. 33, 12670-12678. https://doi.org/10.1523/JNEUROSCI.1086-13.2013 (2013).

37. Tetteh, H., Lee, J., Lee, J., Kim, J. G. \& Yang, S. Investigating long-term synaptic plasticity in interlamellar hippocampus CA1 by electrophysiological field recording. J. Vis. Exp. https://doi.org/10.3791/59879 (2019).

38. Yang, S., Chung, J., Jin, S. H., Bao, S. \& Yang, S. A circuit mechanism of time-to-space conversion for perception. Hear. Res. 366, 32-37. https://doi.org/10.1016/j.heares.2018.05.008 (2018).

39. Wang, T. et al. iTRAQ-based proteomics analysis of hippocampus in spatial memory deficiency rats induced by simulated microgravity. J. Proteom. 160, 64-73. https://doi.org/10.1016/j.jprot.2017.03.013 (2017). 
40. Temple, M. D., Kosik, K. S. \& Steward, O. Spatial learning and memory is preserved in rats after early development in a microgravity environment. Neurobiol. Learn. Mem. 78, 199-216 (2002).

41. Sarkar, P. et al. Proteomic analysis of mice hippocampus in simulated microgravity environment. J. Proteome Res. 5, 548-553 (2006).

42. Frigeri, A. et al. Effect of microgravity on gene expression in mouse brain. Exp. Brain Res. 191, 289-300. https://doi.org/10.1007/ s00221-008-1523-5 (2008).

43. Ranjan, A., Behari, J. \& Mallick, B. N. Cytomorphometric changes in hippocampal CA1 neurons exposed to simulated microgravity using rats as model. Front. Neurol. 5, 77. https://doi.org/10.3389/fneur.2014.00077 (2014).

44. Ishii, M., Tomizawa, K., Matsushita, M. \& Matsui, H. Exposure of mouse to high gravitation forces induces long-term potentiation in the hippocampus. Acta Med. Okayama 58, 143-149 (2004).

45. Bojados, M. \& Jamon, M. The long-term consequences of the exposure to increasing gravity levels on the muscular, vestibular and cognitive functions in adult mice. Behav. Brain Res. 264, 64-73. https://doi.org/10.1016/j.bbr.2014.01.018 (2014).

46. Del Signore, A. et al. Hippocampal gene expression is modulated by hypergravity. Eur. J. Neurosci. 19, 667-677 (2004).

47. Mandillo, S. et al. Effects of acute and repeated daily exposure to hypergravity on spatial learning in mice. Neurosci. Lett. 336, $147-150$ (2003).

48. Ishikawa, C. et al. Effects of gravity changes on gene expression of BDNF and serotonin receptors in the mouse brain. PLoS One 12, $\mathrm{e} 0177833$ (2017).

49. Horii, A. et al. Hippocampal gene expression, serum cortisol level, and spatial memory in rats exposed to hypergravity. J. Vestib. Res. 27, 209-215 (2017).

50. Mitani, K., Horii, A. \& Kubo, T. Impaired spatial learning after hypergravity exposure in rats. Cognit. Brain Res. 22, $94-100$ (2004).

51. Guinan, M. J., Horowitz, J. M. \& Fuller, C. A. Effects of hyperdynamic fields on input-output relationships and long-term potentiation in the rat hippocampus. J. Gravit. Physiol. 5, 31-40 (1998).

52. Miller, J. D., McMillen, B. A., McConnaughey, M. M., Williams, H. L. \& Fuller, C. A. Effects of microgravity on brain neurotransmitter receptors. Eur. J. Pharmacol. 161, 165-171 (1989).

53. Uno, A. et al. Effects of amygdala or hippocampus lesion on hypergravity-induced motion sickness in rats. Acta Otolaryngol. 120, $860-865(2000)$

54. Horrigan, D. J., Fuller, C. A. \& Horowitz, J. M. Effects of hypergravic fields on serotonergic neuromodulation in the rat hippocampus. J. Gravit. Physiol. 4, 21-30 (1997).

55. Bouet, V., Wubbels, R., De Jong, H. \& Gramsbergen, A. Behavioural consequences of hypergravity in developing rats. Dev. Brain Res. 153, 69-78 (2004).

56. Jamon, M. The development of vestibular system and related functions in mammals: Impact of gravity. Front Integr. Neurosci. 8 , 11. https://doi.org/10.3389/fnint.2014.00011 (2014).

57. Bojados, M. \& Jamon, M. Exposure to hypergravity during specific developmental periods differentially affects metabolism and vestibular reactions in adult C57BL/6j mice. Eur. J. Neurosci. 34, 2024-2034. https://doi.org/10.1111/j.1460-9568.2011.07919.x (2011).

58. Wubbels, R. J. \& de Jong, H. A. Vestibular-induced behaviour of rats born and raised in hypergravity. Brain Res. Bull. 52, 349-356 (2000).

59. Hitier, M., Besnard, S. \& Smith, P. F. Vestibular pathways involved in cognition. Front Integr. Neurosci. 8, 59. https://doi.org/10.3389/ fnint.2014.00059 (2014).

60. Smith, P., Geddes, L., Baek, J.-H., Darlington, C. \& Zheng, Y. Modulation of memory by vestibular lesions and galvanic vestibular stimulation. Front. Neurol. 1, 141 (2010).

61. Smith, P. F. et al. The effects of vestibular lesions on hippocampal function in rats. Prog. Neurobiol. 75, 391-405. https://doi. org/10.1016/j.pneurobio.2005.04.004 (2005).

62. Smith, P. F. \& Zheng, Y. From ear to uncertainty: Vestibular contributions to cognitive function. Front. Integr. Neurosci. 7, 84. https ://doi.org/10.3389/fnint.2013.00084 (2013).

63. Stackman, R. W., Clark, A. S. \& Taube, J. S. Hippocampal spatial representations require vestibular input. Hippocampus 12, 291-303 (2002).

64. Rockland, K. S. \& Van Hoesen, G. W. Some temporal and parietal cortical connections converge in CA1 of the primate hippocampus. Cereb. Cortex 9, 232-237 (1999).

65. Horii, A., Russell, N. A., Smith, P. F., Darlington, C. L. \& Bilkey, D. K. Vestibular influences on CA1 neurons in the rat hippocampus: An electrophysiological study in vivo. Exp. Brain Res. 155, 245-250 (2004).

66. Cuthbert, P. C., Gilchrist, D. P., Hicks, S. L., MacDougall, H. G. \& Curthoys, I. S. Electrophysiological evidence for vestibular activation of the guinea pig hippocampus. NeuroReport 11, 1443-1447 (2000).

67. Zucker, R. S. \& Regehr, W. G. Short-term synaptic plasticity. Annu. Rev. Physiol. 64, 355-405. https://doi.org/10.1146/annurev.physi ol.64.092501.114547 (2002).

68. Katz, B. \& Miledi, R. Tetrodotoxin-resistant electric activity in presynaptic terminals. J. Physiol. 203, 459-487 (1969).

69. Chesselet, M.-F. Presynaptic regulation of neurotransmitter release in the brain: Facts and hypothesis. Neuroscience 12, 347-375 (1984).

70. Yang, S. et al. Beta-arrestin-dependent dopaminergic regulation of calcium channel activity in the axon initial segment. Cell Rep. 16, 1518-1526. https://doi.org/10.1016/j.celrep.2016.06.098 (2016).

71. Borisova, T., Krisanova, N. \& Himmelreich, N. Exposure of animals to artificial gravity conditions leads to the alteration of the glutamate release from rat cerebral hemispheres nerve terminals. Adv. Sp. Res. 33, 1362-1367. https://doi.org/10.1016/j.asr.2003.09.039 (2004).

72. Noh, W., Lee, M., Kim, H. J., Kim, K.-S. \& Yang, S. Hypergravity induced disruption of cerebellar motor coordination. Sci. Rep. 10, 4452. https://doi.org/10.1038/s41598-020-61453-w (2020).

73. Beraneck, M., Bojados, M., LeSéach, A., Jamon, M. \& Vidal, P.-P. Ontogeny of mouse vestibulo-ocular reflex following genetic or environmental alteration of gravity sensing. PLoS One 7, 40414 (2012).

74. Mirzoev, T. et al. Divergent anabolic signalling responses of murine soleus and tibialis anterior muscles to chronic $2 \mathrm{~g}$ hypergravity. Sci. Rep. 7, 1-8 (2017).

75. Gnyubkin, V. et al. Effects of chronic hypergravity: From adaptive to deleterious responses in growing mouse skeleton. J. Appl. Physiol. 119, 908-917 (2015).

76. Baker, K. B. \& Kim, J. J. Effects of stress and hippocampal NMDA receptor antagonism on recognition memory in rats. Learn. Memory 9, 58-65 (2002).

77. Cohen, S. J. et al. The rodent hippocampus is essential for nonspatial object memory. Curr. Biol. 23, 1685-1690 (2013).

78. de Lima, M. N., Luft, T., Roesler, R. \& Schröder, N. Temporary inactivation reveals an essential role of the dorsal hippocampus in consolidation of object recognition memory. Neurosci. Lett. 405, 142-146 (2006).

79. Hammond, R. S., Tull, L. E. \& Stackman, R. W. On the delay-dependent involvement of the hippocampus in object recognition memory. Neurobiol. Learn. Mem. 82, 26-34 (2004).

80. de Lima, M. N. M., Laranja, D. C., Bromberg, E., Roesler, R. \& Schröder, N. Pre-or post-training administration of the NMDA receptor blocker MK-801 impairs object recognition memory in rats. Behav. Brain Res. 156, 139-143 (2005). 
81. Hunt, D. L. \& Castillo, P. E. Synaptic plasticity of NMDA receptors: Mechanisms and functional implications. Curr. Opin. Neurobiol. 22, 496-508. https://doi.org/10.1016/j.conb.2012.01.007 (2012).

82. Sidorov, M. S., Kaplan, E. S., Osterweil, E. K., Lindemann, L. \& Bear, M. F. Metabotropic glutamate receptor signaling is required for NMDA receptor-dependent ocular dominance plasticity and LTD in visual cortex. Proc. Natl. Acad. Sci. USA 112, $12852-12857$. https://doi.org/10.1073/pnas.1512878112(2015).

83. Yang, S., Yang, S., Park, J. S., Kirkwood, A. \& Bao, S. Failed stabilization for long-term potentiation in the auditory cortex of FMR1 knockout mice. PLoS One 9, e104691. https://doi.org/10.1371/journal.pone.0104691 (2014).

84. Noh, W., Pak, S., Choi, G., Yang, S. \& Yang, S. Transient potassium channels: Therapeutic targets for brain disorders. Front Cell. Neurosci. 13, 265. https://doi.org/10.3389/fncel.2019.00265 (2019).

85. Tetteh, H., Lee, M., Lau, C. G., Yang, S. \& Yang, S. Tinnitus: Prospects for pharmacological interventions with a seesaw model. Neuroscientist 24, 353-367. https://doi.org/10.1177/1073858417733415 (2018).

\section{Acknowledgements}

We thank Sungchil Yang for constructive comments on this research. This research was supported by Incheon National University (International Cooperative) Research Grant and the Ministry of Education (no. 2016R1D1A1B04930938) for Sunggu Yang, National Research Foundation of Korea (NRF) funded by the Ministry of Education (No. 2018R1A6A1A03025523) for Kyu-Sung Kim.

\section{Author contributions}

S.Y. and K.-s.K. designed and conceptualized the work. J.L., D.J., and H.J. performed electrophysiological and behavioral experiments and analyzed data. S.Y., K.-s.K., and J.L. wrote and revised the manuscript. All authors reviewed the manuscript.

\section{Competing interests}

The authors declare no competing interests.

\section{Additional information}

Correspondence and requests for materials should be addressed to K.K. or S.Y.

Reprints and permissions information is available at www.nature.com/reprints.

Publisher's note Springer Nature remains neutral with regard to jurisdictional claims in published maps and institutional affiliations.

(c) (i) Open Access This article is licensed under a Creative Commons Attribution 4.0 International License, which permits use, sharing, adaptation, distribution and reproduction in any medium or format, as long as you give appropriate credit to the original author(s) and the source, provide a link to the Creative Commons licence, and indicate if changes were made. The images or other third party material in this article are included in the article's Creative Commons licence, unless indicated otherwise in a credit line to the material. If material is not included in the article's Creative Commons licence and your intended use is not permitted by statutory regulation or exceeds the permitted use, you will need to obtain permission directly from the copyright holder. To view a copy of this licence, visit http://creativecommons.org/licenses/by/4.0/.

(c) The Author(s) 2020 